\title{
Direct Physiologic Evidence of a Heteromodal Convergence Region for Proper Naming in Human Left Anterior Temporal Lobe
}

\author{
Taylor J. Abel, ${ }^{1}{ }^{\oplus}$ Ariane E. Rhone, ${ }^{1}$ Kirill V. Nourski, ${ }^{1}$ Hiroto Kawasaki, ${ }^{1}$ Hiroyuki Oya, ${ }^{1}$ Timothy D. Griffiths, ${ }^{3}$ \\ Matthew A. Howard III, ${ }^{1}$ and Daniel Tranel ${ }^{2}$ \\ ${ }^{1}$ Department of Neurosurgery and ${ }^{2}$ Department of Neurology, University of Iowa Hospitals and Clinics, Iowa City, Iowa 52242, and ${ }^{3}$ Newcastle Auditory \\ Group, Medical School, Newcastle University, Newcastle-upon-Tyne NE1 7RU, United Kingdom
}

Retrieving the names of friends, loved ones, and famous people is a fundamental human ability. This ability depends on the left anterior temporal lobe (ATL), where lesions can be associated with impaired naming of people regardless of modality (e.g., picture or voice). This finding has led to the idea that the left ATL is a modality-independent convergence region for proper naming. Hypotheses for how proper-name dispositions are organized within the left ATL include both a single modality-independent (heteromodal) convergence region and spatially discrete modality-dependent (unimodal) regions. Here we show direct electrophysiologic evidence that the left ATL is heteromodal for proper-name retrieval. Using intracranial recordings placed directly on the surface of the left ATL in human subjects, we demonstrate nearly identical responses to picture and voice stimuli of famous U.S. politicians during a naming task. Our results demonstrate convergent and robust large-scale neurophysiologic responses to picture and voice naming in the human left ATL. This finding supports the idea of heteromodal (i.e., transmodal) dispositions for proper naming in the left ATL.

Key words: electrocorticography; language; naming; temporal pole

\section{Introduction}

Numerous studies have demonstrated a crucial role for the left anterior temporal lobe (ATL) in proper naming (Damasio et al., 1996). The deficit associated with left ATL lesions is specific to proper naming (Damasio et al., 1996) and occurs regardless of input modality (Belfi and Tranel, 2014), but is dissociated from conceptual knowledge retrieval (Tranel et al., 1997). For example, a patient may lose the ability to name famous persons from pictures or voices, but retain normal recognition of those persons and normal ability to name nonunique entities, such as tools. This has prompted the hypothesis that the left ATL functions as a convergence region for proper-name retrieval (Damasio et al., 2004). Per this theory, visual and auditory representations of proper nouns (i.e., unique entities) activate shared cortex within the left ATL and activate a common circuit for proper-name retrieval. An alternative hypothesis is that transmodal ATLassociated naming deficits occur secondary to dysfunction of the

\footnotetext{
Received Aug. 14, 2014; revised Nov. 24, 2014; accepted Dec. 3, 2014.

Author contributions: T.J.A., M.A.H., and D.T. designed research; T.J.A. and A.E.R. performed research; H.K., H.O., and T.D.G. contributed unpublished reagents/analytic tools; T.J.A., A.E.R., and K.V.N. analyzed data; T.J.A., A.E.R., K.V.N., and D.T. wrote the paper.

This work was supported by the National Institutes of Health (Grants NIH F32-NS087664, NIH R01-DC004290, NIH UL1RR024979), McDonnell Foundation Collaborative Action Award \#220020387, the Hoover Fund, and the Hearing Health Foundation. We thank Ken Manzel for his assistance in data collection.

The authors declare no competing financial interests.

Correspondence should be addressed to Taylor J. Abel, MD, University of lowa Hospitals and Clinics, 200 Hawkins Drive, lowa City, lowa 52242. E-mail: taylor-abel@uiowa.edu.

DOI:10.1523/JNEUROSCI.3387-14.2015

Copyright $\odot 2015$ the authors $\quad 0270-6474 / 15 / 351513-08 \$ 15.00 / 0$
}

semantic network and are not dissociated from conceptual knowledge retrieval (Lambon Ralph, 2014). Transmodal convergence of auditory and visual pathways in the left ATL is supported by nonhuman primate studies showing visual input to the ventral ATL and auditory input to the dorsal ATL (Morán et al., 1987) and human magnetic resonance (MR) tractography studies showing graded convergence of visual and auditory inputs to the ATL (Binney et al., 2012).

Although left ATL lesions are known to cause transmodal deficits (e.g., impaired visual and auditory proper naming), there is an active debate regarding the neurophysiologic basis for transmodal naming deficits (Skipper et al., 2011; Belfi and Tranel, 2014; Lambon Ralph, 2014). One possibility is that the left ATL contains spatially segregated cortex that has unimodal response properties and that acts as an intermediary for modality-specific name retrieval. Another hypothesis is that the left ATL contains cortex with heteromodal (i.e., transmodal) response characteristics, which activate congruously for visual and auditory naming, as a single intermediary for modality-independent name retrieval. Limitations inherent to functional neuroimaging and lesion approaches make studying the neurophysiology of naming in the ATL difficult (Ojemann et al., 1997; Devlin et al., 2000). Because of these methodological limitations, the unimodalversus-heteromodal nature of neural representations within the left ATL are poorly understood and evidence exists for both unimodal (Barsalou et al., 2003; Skipper et al., 2011) and heteromodal (Pobric et al., 2010b; Drane et al., 2013) mechanisms for naming within the ATL. 
Table 1. Demographic and clinical data

\begin{tabular}{|c|c|c|c|c|c|c|c|c|c|}
\hline Subject & Age & Sex & Education $^{a}$ & Handedness $^{b}$ & Language dominance $^{c}$ & Age at epilepsy onset & Seizure focus & Pathology & Medications \\
\hline L206 & 48 & Male & 12 & +100 & Left & 33 & Left temporal & Mesial temporal sclerosis & Carbamazepine, zonisamide \\
\hline L242 & 49 & Male & 14 & -50 & Left & 16 & Left temporal & Focal cortical dysplasia & None \\
\hline L258 & 38 & Male & 16 & +90 & Left & 29 & Multifocal: left frontal and temporal & Not applicable & None \\
\hline
\end{tabular}

${ }^{a}$ Years of formal schooling.

${ }^{b}$ Derived from the Geschwind-Oldfield Handedness Questionnaire (Oldfield, 1971), which runs from full right handedness $(+100)$ to full left handedness $(-100)$.

'Determined by Wada test (Wada and Rasmussen, 2007).

\section{Table 2. Neuropsychological data}

\begin{tabular}{|c|c|c|c|}
\hline Neuropsychological test & L206 & L242 & L258 \\
\hline \multicolumn{4}{|l|}{ Wechsler Adult Intelligence Scale scores (WAIS-IV) } \\
\hline Verbal Comprehension Index (100 \pm 15$)$ & 105 & 107 & 85 \\
\hline Perceptual Reasoning Index (100 \pm 15$)$ & 81 & 88 & 81 \\
\hline Full Scale IQ (100 \pm 15$)$ & 91 & 93 & 89 \\
\hline Similarities $(10 \pm 3)$ & 11 & 11 & 9 \\
\hline Information (10 \pm 3$)$ & 11 & 12 & 7 \\
\hline Vocabulary $(10 \pm 3)$ & 11 & 11 & 6 \\
\hline Block design $(10 \pm 3)$ & 6 & 8 & 7 \\
\hline Matrix reasoning $(10 \pm 3)$ & 8 & 9 & 5 \\
\hline Visual puzzles $(10 \pm 3)$ & 6 & 7 & 8 \\
\hline Digit span $(10 \pm 3)$ & 9 & 7 & 7 \\
\hline Arithmetic $(10 \pm 3)$ & 10 & 9 & 13 \\
\hline Symbol search $(10 \pm 3)$ & 8 & 7 & 11 \\
\hline Coding $(10 \pm 3)$ & 7 & - & 12 \\
\hline Boston Naming Test (\#/60) & 53 & 50 & 45 \\
\hline Complex Ideational Material Test (\#/12) & 12 & 12 & 12 \\
\hline Controlled Oral Word Association Test (percentile) & 11 & 25 & 47 \\
\hline Facial Recognition Test (\#/54) & 45 & 49 & 41 \\
\hline \multicolumn{4}{|l|}{ Trail Making Test } \\
\hline Part A (T-score) & 45 & 55 & 53 \\
\hline Part B (T-score) & 42 & 39 & 49 \\
\hline \multicolumn{4}{|l|}{ Auditory Verbal Learning Test } \\
\hline Trial 1 (\#/15) & 5 & 6 & 6 \\
\hline Trial $5(\# / 15)$ & 8 & 10 & 10 \\
\hline 30 min recall (\#/15) & 0 & 4 & 7 \\
\hline Benton Visual Retention Test (\#/10) & 6 & 7 & 7 \\
\hline Speech rating & $\begin{array}{l}\text { Mild word finding } \\
\text { difficulty }\end{array}$ & Normal & Normal \\
\hline
\end{tabular}

To evaluate this hypothesis, we studied electrocorticographic (ECoG) recordings from the left ATL in patients with intracranial electrodes placed for seizure localization. Using a recently developed electrode array designed for dense coverage of the human ATL (Abel et al., 2014), we recorded the electrophysiologic correlates of picture and voice proper naming in the left ATL. Given the heteromodal nature of proper-naming deficits associated with left ATL lesions and the convergence of visual and auditory inputs to the left ATL, we evaluated the hypothesis that cortex in the left ATL would demonstrate heteromodal responses for visual and auditory proper naming.

\section{Materials and Methods}

Participants. ECoG recordings were obtained from the left hemisphere of three neurosurgical patients (all males; ages 39, 50, and 51 years; Table 1) undergoing intracranial monitoring for seizure focus localization. Written informed consent was obtained from each subject. The research protocol was approved by the University of Iowa Human Subjects Review Board.

All participants underwent preoperative neuropsychological evaluation (Table 2). Two subjects were right-handed (Subject L242 was lefthanded), but all three subjects demonstrated left language lateralization by Wada testing (Wada and Rasmussen, 2007). All subjects were of normal intelligence. Subjects L242 and L258 exhibited subtle preoperative naming deficits that did not impact their ability to participate in this study. All subjects had interictal discharges recorded from the ATL and subject L206 had ictal epileptiform activity arising from the ATL, but there was no indication that these epileptiform abnormalities impacted experimental naming-task performance (see Results).

Electrode implantation. Dense coverage of the ATL was achieved using a standard anteromedial strip electrode in conjunction with a custom electrode array (Ad Tech Medical) specialized to cover the convexity of temporopolar cortex (Fig. 1a; Abel et al., 2014). Intracranial electrodes were placed using a standard left frontotemporal craniotomy in all subjects (Fig. 1b). Each subject also had placement of electrodes over posterior fusiform gyrus (pFG) and superior temporal gyrus (STG), which varied in density depending on the clinical need for electrode coverage. Each subject underwent whole-brain MRI and CT scanning before electrode implantation. To localize electrodes on each subject's 3D-rendered brain MR, high-resolution T1-weighted structural MRIs (in-plane resolution, $0.78 \times 0.78 \times 1.0 \mathrm{~mm}$ ) were obtained both before and after electrode implantation. Preimplantation and postimplantation MRIs were coregistered using a 3D rigid fusion algorithm (Analyze version 8.1 software, Mayo Clinic). Coordinates for each electrode contact obtained from postimplantation MRI volumes were transferred to preimplantation MRI volumes.

Task. Subjects performed naming of U.S. presidents (i.e., proper nouns) by their pictures and voices in separate blocks. To elicit physiologic responses relevant to our main hypothesis, unique concrete entities were chosen for the experimental naming tasks. Picture stimuli consisted of 150 pictures of Barack Obama, Bill Clinton, and George W. Bush (50 unique pictures for each president). Pictures showed each president from various angles and in different contexts. Pictures were obtained from the Internet and did not contain any text. Voice stimuli consisted of 150 different 1.5 s voice clips of Barack Obama, Bill Clinton, and George W. Bush (50 unique voice clips for each president) obtained from speech or interview clips downloaded from the Internet.

Stimulus randomization and presentation were performed with Presentation Software (version 14.9, www.neurobs.com). Visual stimuli were presented on a computer monitor placed $\sim 1 \mathrm{~m}$ from the subject's face. Voice stimuli were presented at a comfortable volume (as determined by each subject) via insert earphones embedded in custom-made earmolds. Pictures were presented for $1 \mathrm{~s}$ and voice clips were presented for $1.5 \mathrm{~s}$. Voice stimuli were presented for longer because voices typically take longer to identify than pictures (González et al., 2011). In the case of visual stimuli, the picture was replaced by a red cross that turned green $1 \mathrm{~s}$ after picture offset (2s after beginning of trial; Fig. 1c) prompting the patient to verbally respond with the name of the picture. For voice naming, a red cross was present on the computer monitor during sound presentation until $1 \mathrm{~s}$ following the stimulus. This cross turned green $2.5 \mathrm{~s}$ after stimulus onset and cued the subject to overtly name the person speaking. A microphone located near the subject recorded each verbal response and triggered the next stimulus, resulting in a variable intertrial interval (but not $<1 \mathrm{~s}$ ).

Control experiments were performed in separate blocks in the same subjects. These experiments were performed as part of different research projects (Tsuchiya et al., 2008; Nourski et al., 2014), but were used as post hoc controls given their use as simple face and voice stimuli. For the face control task, faces with neutral expressions were presented for $500 \mathrm{~ms}$ among other visual stimuli and subjects were asked to perform a target detection task (press a button when a fixation cross changed color or when a single visual category was presented sequentially). For the voice control task, subjects were presented with speech syllables (/aba/ and 

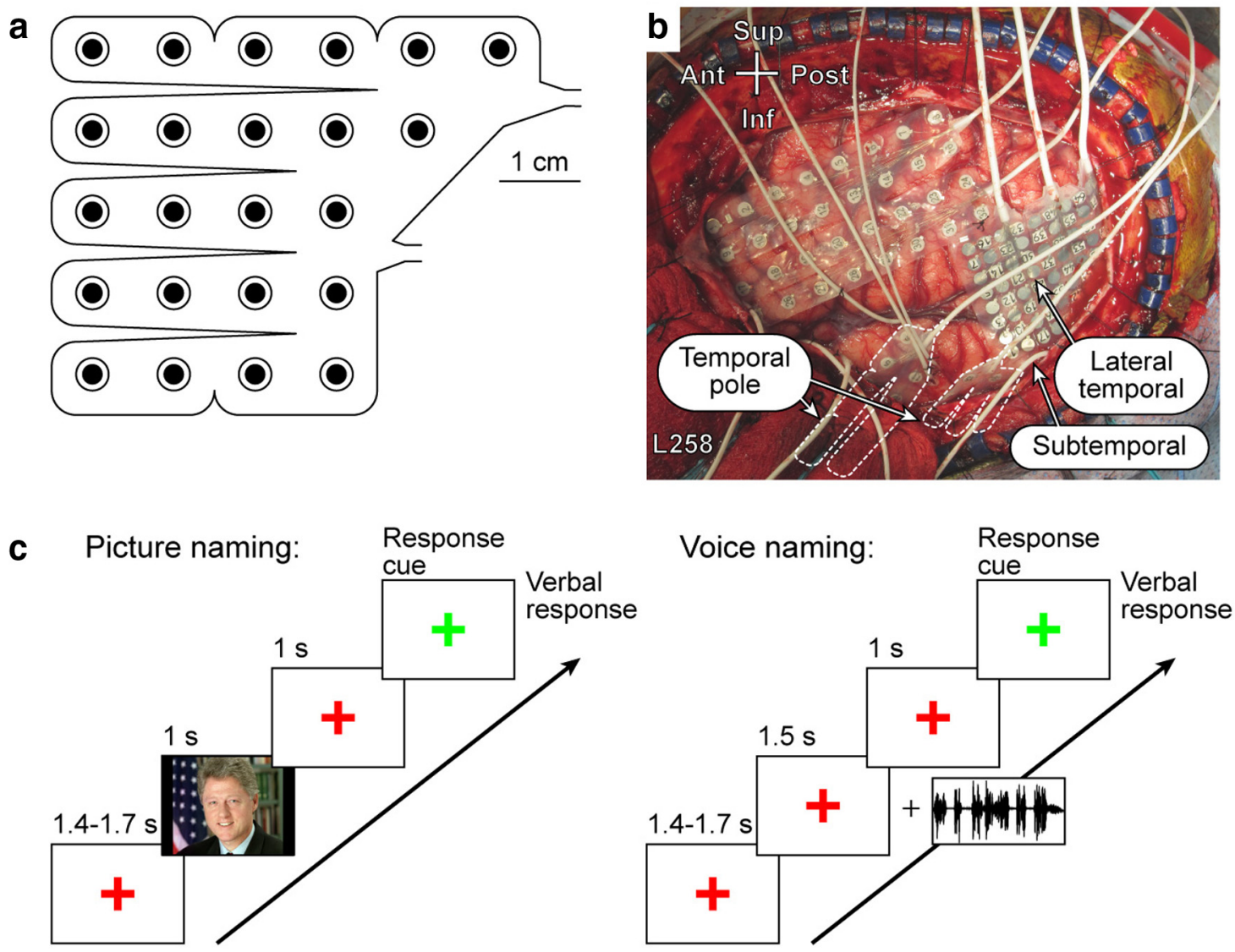

Figure 1. Methods for performing intracranial recordings from the human ATL and experimental task paradigms. $\boldsymbol{a}$, Schematic of a customized ATL electrode array that is implanted clinically for seizure localization and provides dense coverage of the human ATL. $\boldsymbol{b}$, Intraoperative photograph showing placement of intracranial electrodes for seizure localization and cognitive mapping. In this particular example, the ATL electrode array is sectioned in half to preserve a vein on the basal surface of the temporal lobe. $c$, Schematic depiction of picture-naming and voice-naming tasks.

/ada/; approximate duration, $500 \mathrm{~ms}$ ) in a two-alternative forced-choice stimulus identification task.

Recording. ECoG signals were recorded continuously, amplified, filtered (1-1000 $\mathrm{Hz}$ bandpass, $12 \mathrm{~dB}$ /octave rolloff), digitized at a sampling rate of $2034 \mathrm{~Hz}$, and stored for subsequent offline analysis. Data were downsampled to $1000 \mathrm{~Hz}$, filtered to remove $60 \mathrm{~Hz}$ line noise and its harmonics, and segmented into $4 \mathrm{~s}$ trial epochs, from -1 to $3 \mathrm{~s}$ relative to stimulus onset.

Time-frequency analysis was implemented using two methods. For visualization (Fig. 2), multitaper spectral analysis (Thomson, 1982) was performed (150 ms window, $50 \mathrm{~ms}$ step size, three tapers). For statistical analysis comparing conditions of interest, event-related band power (ERBP) in the beta band $(14-30 \mathrm{~Hz}$, obtained from the ECoG signal using 100-order finite impulse response filter) was calculated relative to a $500 \mathrm{~ms}$ prestimulus baseline $(-800$ to $-300 \mathrm{~ms}$ before the onset of each trial). This frequency range was selected based on spectral profiles of all recording sites on the ATL (see Fig. 4), which demonstrated robust power change in low frequencies during both naming tasks.

To assess responsivity, average beta or high-gamma $(75-150 \mathrm{~Hz})$ ERBP in a $1 \mathrm{~s}$ window (300-1300 ms poststimulus onset) from each anatomically defined site was compared with prestimulus baseline activity with a one-tailed $t$ test, corrected for multiple comparisons using false discovery rate criterion (Benjamini and Hochberg, 1995), with significance threshold set to $q=0.01$. To determine possible response in visual and auditory control experiments, analysis time windows were adjusted to $200-900$ and $300-800 \mathrm{~ms}$ poststimulus for the face and voice control experiment, respectively, and significance threshold set to $q=0.01$.

\section{Results}

\section{Behavioral performance}

The accuracy of voice and picture naming was determined for each subject. Across all subjects, the overall accuracy of picture naming was $91.7 \%$ and overall accuracy of voice naming was $81.0 \%$. Subject L206 correctly named $87.5 \%$ of pictures and $80.6 \%$ of voices. Subject L242 correctly named $88.9 \%$ of pictures and $69.2 \%$ of voices. Subject L258 correctly named $98.7 \%$ of pictures and $93.3 \%$ of voices. For the picture-naming task, most errors consisted of either the response "don't know" or response omission (i.e., a skipped trial). For the voice-naming task, most error responses were "don't know," and there were also a number of substitution errors (Bill Clinton for George Bush and vice versa). ECoG data from trials associated with incorrect responses were excluded from subsequent analysis.

\section{Responses to picture and voice naming}

Picture and voice stimuli used in the naming task elicited robust responses within the pFG and STG, respectively (Fig. 2), consistent with the pattern of predominantly unimodal activation of these brain regions. ERBP analysis demonstrated that this unimodal stimulus-induced increase in activity was mostly confined to gamma $(30-70 \mathrm{~Hz})$ and high gamma (70-150 ECoG frequency bands; Fig. 2, X, Y). In contrast, both pictures and voices of famous persons induced responses within the left ATL during the naming task (Fig. 2, Z). Further, time-frequency analysis revealed that this heteromodal activation of the ATL had a later latency compared with responses from unimodal areas, and the observed changes in ECoG power were confined to lower frequencies.

To compare the spectral profiles of responses between unimodal and heteromodal cortices, ERBP measured from 0 to $2 \mathrm{~s}$ 
a

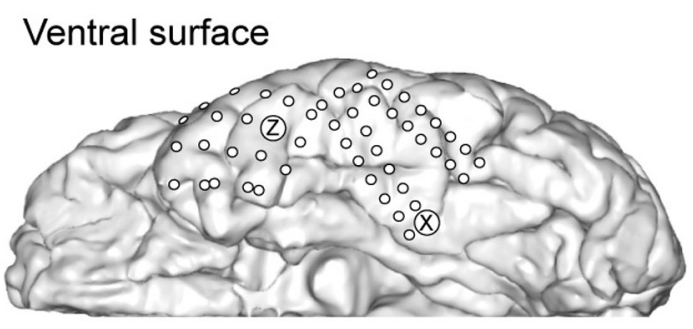

\section{Lateral surface}

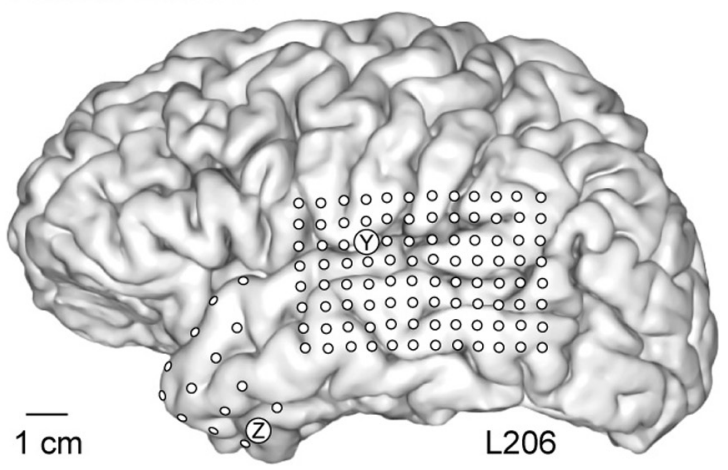

b

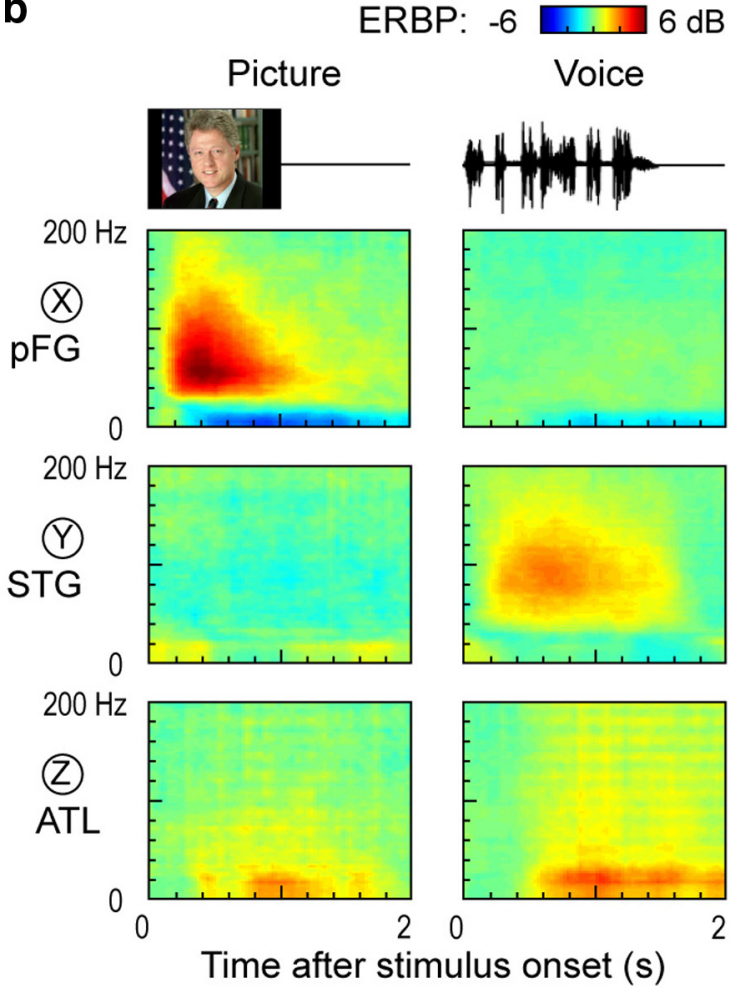

Figure 2. Responses from representative sites demonstrating unimodal activation of $\mathrm{pFG}(\mathrm{X})$ during picture naming and STG $(\mathrm{Y})$ during voice naming, but heteromodal activation of the left ATL (Z) for both picture and voice naming. $\boldsymbol{a}$, (T-MR coregistered brain renderings demonstrating location of the implanted electrode arrays and the three representative sites on the brain of subject L206. $\boldsymbol{b}$, Time-frequency plots of ERBP measured from representative sites on pFG (X), STG (Y), and ATL (Z).
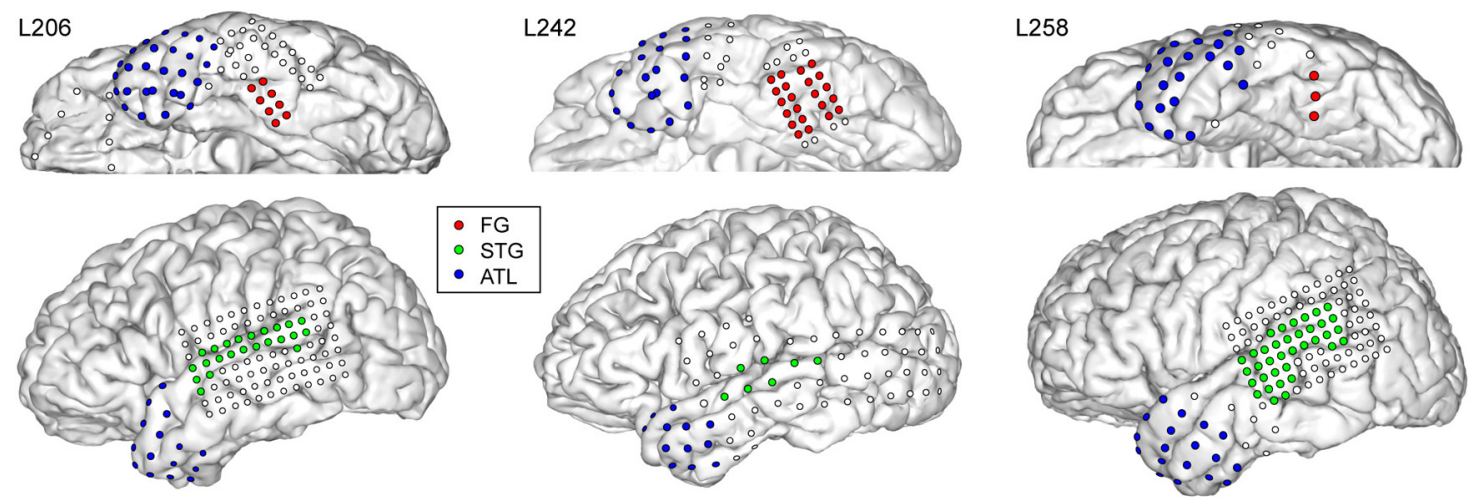

Figure 3. Sites within the three anatomical regions of interest (pFG, STG, and ATL, shown by red, green, and blue circles, respectively) in the three experimental subjects. Open circles denote electrode sites that were beyond the regions of interest; data from these sites were excluded from the analyses.

after stimulus onset was averaged across all sites within the three anatomical regions of interest (pFG, STG, and ATL; Fig. 3) and plotted as a function of ECoG frequency for each region and task (Fig. 4). Responses from pFG and STG to pictures and voices, respectively, were characterized by increases in gamma and highgamma power with concomitant attenuation of power in lowerfrequency bands [beta $(14-30 \mathrm{~Hz})$ and below]. In contrast, responses from the left ATL were characterized by task-related power increases at lower frequencies that were maximal in the beta band. ATL sites did not exhibit increases in high gamma as is frequently observed when other brain regions are activated (Crone et al., 1998; Miller et al., 2007; Tsuchiya et al., 2008; Steinschneider et al., 2011).
Spatial distribution, temporal characteristics, and task specificity of naming responses

To evaluate the spatial extent of ATL responses, power changes in the beta band measured from 300 to $1300 \mathrm{~ms}$ following stimulus onset were evaluated for statistical significance. The beta ECoG band was selected for analysis since it is a classically described frequency band that best corresponds to the spectral profile of ERBP measured from the left ATL in our experiments (Fig. 4; Pfurtscheller et al., 1997). The time window for statistical analysis was selected based on qualitative analysis of the time-frequency characteristics of responses as exemplified above (Fig. 2). Cortical sites that exhibited significant $(q<0.01)$ responses for picturenaming, voice-naming, or both picture-naming and voice- 


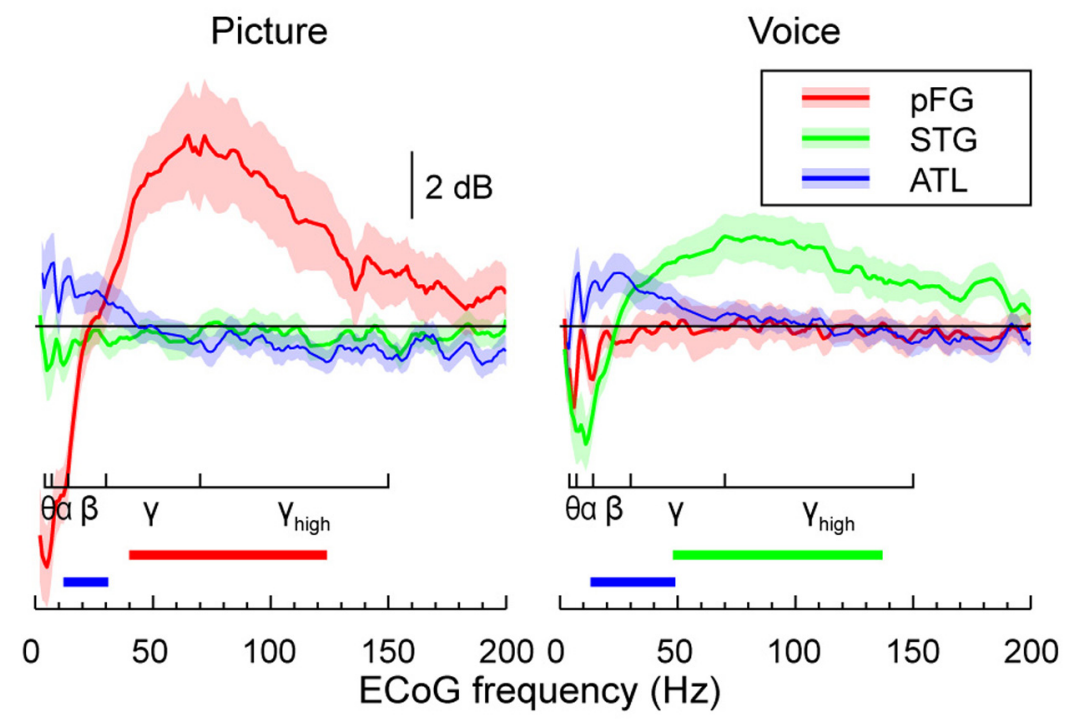

Figure 4. Spectral profile of ERBP during picture (left) and voice naming (right) of proper nouns in pFG, STG, and ATL averaged across all subjects. Thick lines and shaded areas represent mean ERBP across ECOG frequencies and its $95 \%$ confidence interval, respectively. Second $x$-axis shows conventional $\mathrm{ECOG}$ frequency bands [theta $(\theta), 4-8 \mathrm{~Hz}$; alpha $(\alpha), 8-14 \mathrm{~Hz}$; beta $(\beta), 14-30$ $\mathrm{Hz}$; gamma $(\gamma), 30-70 \mathrm{~Hz}$; high gamma $\left(\gamma_{\text {high }}\right), 70-150 \mathrm{~Hz}$. ECoG frequency ranges that correspond to ERBP increases beyond the lower limit of the $95 \%$ confidence interval are shown as horizontal color bars.

naming tasks are shown in Figure 5. These direct recordings reveal a complex tessellated pattern of functional organization with half of the cortical sites processing both auditory and visual naming information, while many immediately adjacent sites respond to only one sensory modality. A large proportion of responsive cortical sites included the ventrolateral ATL. In two subjects (L206 and L242; Fig. 5), sites that were selectively active during picture naming were confined to the ventromedial aspect of the ATL, while voice-selective sites were located more laterally.

The timing of heteromodal neural responses within the left ATL is illustrated in the bottom panels of Figure 5 for three representative sites. The onset of the earliest beta-band ERBP increases were observed $300 \mathrm{~ms}$ following picture or voice presentation and reached maximal response magnitude within $1 \mathrm{~s}$. Naming in response to a voice stimulus was typically associated with a more prolonged power increase than was observed in response to pictures (data not shown).

The spatial distribution of significant responses in the highgamma band was assessed for both picture-naming and voicenaming tasks (Fig. 6). The picture-naming task elicited significant high-gamma responses in $\mathrm{pFG}$ in all subjects. Conversely, voice naming elicited significant high-gamma responses in STG in all subjects. Both picture-naming and voice-naming tasks resulted in significant responses from the ATL. However, no ATL cortex sites demonstrated a significant high-gamma response for both picturenaming and voice-naming tasks. There were sporadic heteromodal significant high-gamma responses in the posterolateral temporal lobe, which likely represent Wernicke's area (Miller et al., 2007), and also pFG.

Next, we sought to determine whether the observed responses to picture and voice stimuli were specific for the naming task or reflected a more general sensory integration. To that end, we examined left ATL responses to visual stimuli (faces; Tsuchiya et al., 2008) in a target detection task and auditory (voice) stimuli in a phoneme identification task (Nourski et al., 2014). In both control experiments, examination of ECoG power in the beta band $(14-30 \mathrm{~Hz})$ failed to reveal significant activation (at $q=0.01$ ).

\section{Discussion}

Using dense intracranial electrode coverage, we observed robust electrophysiologic responses within the left ATL to pictures and voices of famous persons during a proper-naming task. During the naming task, picture and voice stimuli elicited nearly identical spectral response patterns at heteromodal cortical sites in the left ATL. This study provides the first electrophysiologic evidence to support the view that the left ATL contains a heteromodal hub (i.e., convergence region for retrieval of proper names; Tranel et al., 2005; Pobric et al., 2010a; Drane et al., 2013). We found that cortical sites with heteromodal activation properties were surrounded by cortex with unimodal activation properties, consistent with the finding of graded convergence in the left ATL (Binney et al., 2012). This is in contrast to the idea that proper-name retrieval within the left ATL occurs purely through spatially distinct neuronal populations that demonstrate modality selectivity (Barsalou et al., 2003; Skipper et al., 2011). The idea of heteromodal name retrieval is supported by lesion studies (Belfi and Tranel, 2014; Waldron et al., 2014), transcranial magnetic stimulation studies (Pobric et al., 2010a), and MR tractography connectivity data (Binney et al., 2012), but direct electrophysiologic evidence for heteromodal responses of the left ATL during proper naming has not been described until now. Additionally, intracranial recordings have identified heteromodal cortex in nonunique visual and auditory naming tasks (Cervenka et al., 2013). With evidence for both unimodal and heteromodal responses from the left ATL, this electrophysiologic study reconciles neuroimaging and lesion-based models that posit modality-dependent left ATL subregions (Barsalou et al., 2003) with those promoting modalityindependent (i.e., heteromodal) dispositions for naming in the left ATL (Damasio et al., 2004; Lambon Ralph, 2014).

We found that picture-naming and voice-naming stimuli resulted in increased power in the sub- $50 \mathrm{~Hz}$ frequency range in the left ATL. The spectral profile of power increases to propernaming stimuli in the left ATL spanned the classically described beta $(14-30 \mathrm{~Hz})$ and, in part, the gamma $(>30 \mathrm{~Hz})$ ECoG frequency bands. Quantitative analyses of responses focused on the beta range, since it is a classically recognized ECoG frequency band that best corresponds to our spectral analysis (Fig. 4). It is well recognized that low-frequency oscillations (typically $<30$ $\mathrm{Hz}$ ) are ubiquitous throughout the brain, with different spectral components modulated by specific tasks (Pfurtscheller et al., 1997; Tallon-Baudry et al., 2001; Hermes et al., 2014). The physiologic mechanism for the relatively low frequency power increases we see in the left ATL is not known, but it is possible that power alterations in this frequency range are driven by input from distant brain regions. Furthermore, the significance of lowfrequency oscillations in higher cognitive functions are unknown (Canolty and Knight, 2010). The finding of increased ECoG ERBP in the left ATL in a frequency distribution spanning both beta and gamma bands is surprising given previous ECoG lan- 

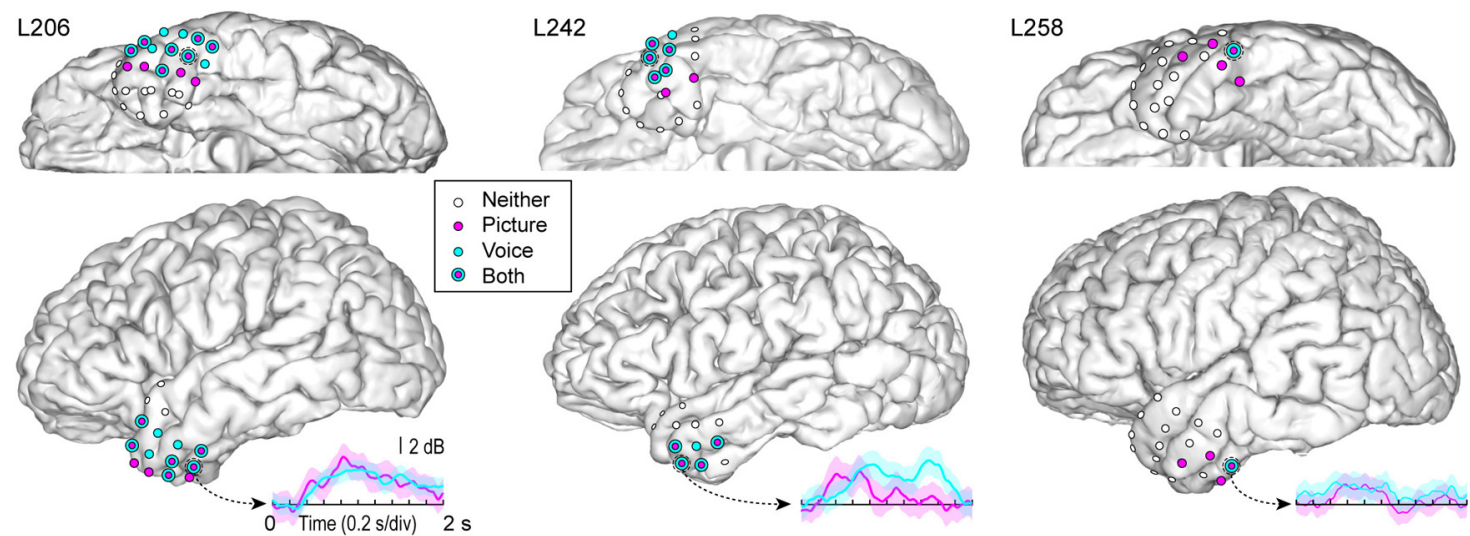

Figure 5. Spatial distribution of beta ERBP responses from the ATL. Sites that exhibited significant responses during picture naming and voice naming are shown in magenta and cyan, respectively. Open circles denote recording sites that were included in the analysis on anatomical grounds (Fig. 3), but did not feature significant beta response to either stimulus. Half of responsive electrode sites exhibited a heteromodal response pattern (i.e., significant induced power for both picture and voice naming). The time course of beta ERBP responses during picture and voice naming is plotted for three representative heteromodal sites (dashed circles) in magenta and cyan, respectively. Thick lines and shaded areas represent mean ERBP across ECoG frequencies and its $95 \%$ confidence interval, respectively.
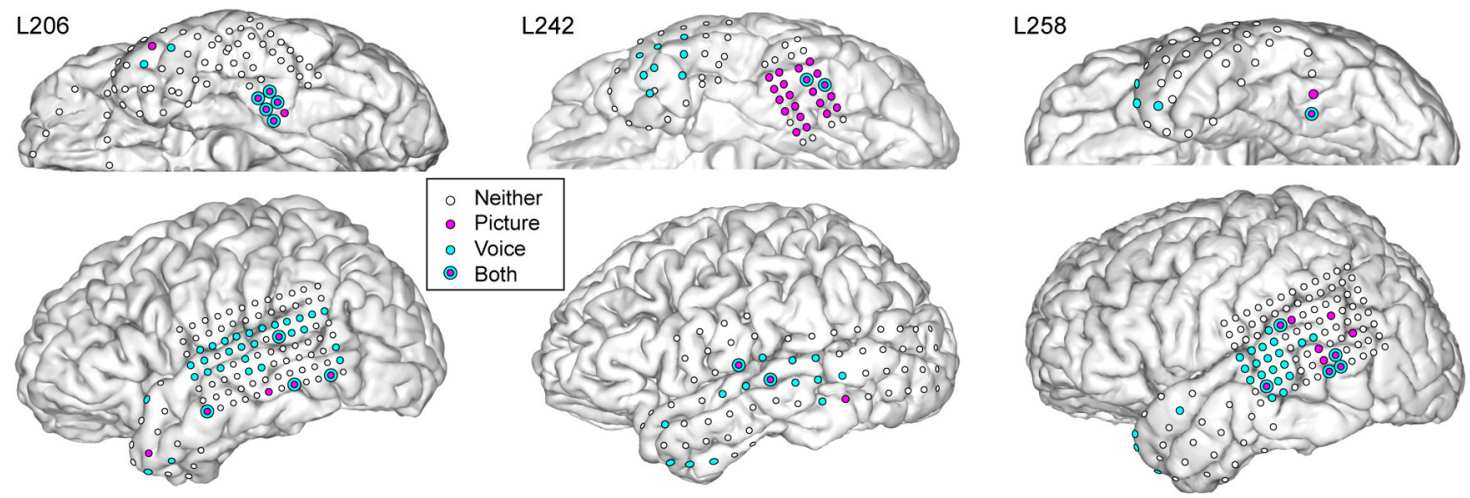

Figure 6. Spatial distribution of high-gamma ERBP responses from the ATL, pFG, and STG. Sites that exhibited significant responses during picture naming and voice naming are shown in magenta and cyan, respectively. Open circles represent recording sites included in analysis, but not showing significant high-gamma-band responses. There were no significant heteromodal high-gamma responses from ATL cortex. All three subjects had heteromodal high-gamma response sites on the posterolateral temporal lobe, perhaps representing the classically described Wernicke's area (Miller et al., 2011).

guage studies showing increased power at higher frequencies in classical language cortex (Towle et al., 2008; Miller et al., 2011). If power changes predominately occur in the sub-50 $\mathrm{Hz}$ range in the left ATL, it is possible that some of the variability of prior ATL fMRI studies results from poor correlation between the BOLD signal and ECoG power at lower frequencies (Ojemann et al., 1997; Devlin et al., 2000). A large number of factors have been shown previously to influence responses of the ATLs on BOLD fMRI (Devlin et al., 2000; Visser et al., 2010b). The fMRI BOLD signal is thought to best correlate with high-gamma oscillations in multiple brain regions (Lachaux et al., 2007; Conner et al., 2011; Hermes et al., 2014). In contrast, lower frequencies are not correlated as well to the BOLD signal and may also exhibit greater variability in BOLD signal correlation (Conner et al., 2011). Therefore, based on the results of the present study, lack of BOLD signal change in the left ATL for some tasks may not truly reflect lack of neural activity in the ATL as was previously thought.

Our analysis of high-gamma responses from ATL, pFG, and STG cortex also demonstrate significant responses. Unsurprisingly, high-gamma responses from $\mathrm{pFG}$ and STG were unimodal for picture naming and voice naming, respectively, as previously described (Tsuchiya et al., 2008; Steinschneider et al., 2011). Also as expected, we found heteromodal response sites on the posterolat- eral temporal lobe, which likely reflects Wernicke's area as previously described (Miller et al., 2011). Interestingly, we observed heteromodal high-gamma responses from pFG, particularly in L206. Importantly, while we observed unimodal high-gamma responses from the ATL for both picture and voice naming, there were no heteromodal high-gamma response sites in the ATL, unlike what was observed for the beta rhythm.

Results from both PET (Gorno-Tempini et al., 1998; Grabowski et al., 2001) and fMRI (Visser et al., 2010a; Ross and Olson, 2012) functional neuroimaging studies have pointed to physiologic activation of the ATL during naming tasks. These functional neuroimaging results support neuropsychological (Damasio et al., 1996; Drane et al., 2013) and transcranial magnetic stimulation studies (Pobric et al., 2010a) that demonstrate that the left ATL is important for proper-name retrieval. Our intracranial recordings demonstrate spatially broad responsivity of the left ATL during both picture and voice naming that emerged within $300 \mathrm{~ms}$ and peaked within $1 \mathrm{~s}$ following stimulus onset for both picture and voice stimuli. Approximately half of responsive sites (14 of 29 in three subjects) were responsive during both visual and auditory naming, which suggests that name retrieval within the left ATL (as seen in lesion studies) could be mediated by heteromodal cortex. This idea is consistent with 
recent lesion studies reporting deficits in voice and melody naming (with proper nouns) in patients with left temporopolar damage (Belfi and Tranel, 2014; Waldron et al., 2014). Other authors, however, have cited neuroanatomical data (Kondo et al., 2003) and BOLD fMRI studies (Skipper et al., 2011) that support a view of completely distinct sensory subregions of the ATL. Our results support the existence of both heteromodal and unimodal cortical responses in the left ATL. As already discussed, our data suggest that the physiologic correlates of voice-naming and picturenaming stimuli in the ATL may not be completely reflected in the BOLD signal. In two of our subjects, we found ventral electrodes that showed preferential responsivity to picture-naming stimuli and lateral electrodes that showed preferential responsivity to voice-naming stimuli. This finding is consistent with the view that the ATL exhibits graded convergence of visual and auditory pathways along its rostral-caudal axis, with maximal fiber convergence at the apex of the ATL (Binney et al., 2012). This view is also supported by anatomic MR tractography analyses that show extensive longitudinal, diagonal, and lateral connectivity along the rostral-caudal axis of the temporal lobe (Binney et al., 2012). Per these ideas, our finding of modality-selective and modalityindependent cortical sites may reflect the relative density of visual and auditory inputs to the left ATL.

Other studies have used intracranial recordings to examine responses of the ATL (Chan et al., 2011; Cervenka et al., 2013). Cervenka and colleagues reported rare heteromodal response sites in the human ATL by evaluating power in the high-gamma band (Cervenka et al., 2013). In our study, we did not find heteromodal responses from the ATL in the high-gamma band, despite having greater coverage density in our three subjects. Chan and colleagues reported semantic category-specific responses with depth recordings from the anterior and medial temporal lobe (Chan et al., 2011). Together with these previous findings, the results of the present study provide important groundwork for further investigation of the ATL by human intracranial recordings.

Our findings are consistent with the idea that the left ATL contains a heteromodal hub that harbors a modality-independent disposition for retrieval of proper names for unique entities, which may be surrounded by regions that are more modality-selective. This pattern of cortical activation may be the result of graded convergence of visual and auditory inputs to the left ATL. This heteromodal hub has been referred to as a convergence region, which is category specific (i.e., proper nouns; Damasio et al., 2004). Convergence regions such as this are proposed to be third-party intermediaries between conceptual knowledge (i.e., recognition) and word form, and thus contain a dispositional representation for retrieval of either word form or conceptual knowledge. Alternative views of the ATL posit that the left ATL is not selective for unique entities and rather dysfunction of the left ATL (and right ATL in some cases) results in a more generalized anomia (Pobric et al., 2007, 2010b; Lambon Ralph, 2014). In this view, the left ATL-associated naming deficit may occur due to dysfunction of the semantic network and is thus not dissociated from conceptual knowledge retrieval (Lambon Ralph et al., 2001). In conclusion, our data provide the first direct physiologic evidence to demonstrate heteromodal activation of the human left ATL to picture and voices in a proper-naming task.

\section{References}

Abel TJ, Rhone AE, Nourski KV, Granner MA, Oya H, Griffiths TD, Tranel DT, Kawasaki H, Howard MA 3rd (2014) Mapping the temporal pole with a specialized electrode array: technique and preliminary results. Physiol Meas 35:323-337. CrossRef Medline
Barsalou LW, Kyle Simmons W, Barbey AK, Wilson CD (2003) Grounding conceptual knowledge in modality-specific systems. Trends Cogn Sci 7:84-91. CrossRef Medline

Belfi AM, Tranel D (2014) Impaired naming of famous musical melodies is associated with left temporal polar damage. Neuropsychology 28:429435. CrossRef Medline

Benjamini Y, Hochberg Y (1995) Controlling the false discovery rate-a practical and powerful approach to multiple testing. J Roy Stat Soc B Met 57:289-300.

Binney RJ, Parker GJ, Lambon Ralph MA (2012) Convergent connectivity and graded specialization in the rostral human temporal lobe as revealed by diffusion-weighted imaging probabilistic tractography. J Cogn Neurosci 24:1998-2014. CrossRef Medline

Canolty RT, Knight RT (2010) The functional role of cross-frequency coupling. Trends Cogn Sci 14:506-515. CrossRef Medline

Cervenka MC, Corines J, Boatman-Reich DF, Eloyan A, Sheng X, Franaszczuk PJ, Crone NE (2013) Electrocorticographic functional mapping identifies human cortex critical for auditory and visual naming. Neuroimage 69:267-276. CrossRef Medline

Chan AM, Baker JM, Eskandar E, Schomer D, Ulbert I, Marinkovic K, Cash SS, Halgren E (2011) First-pass selectivity for semantic categories in human anteroventral temporal lobe. J Neurosci 31:18119-18129. CrossRef Medline

Conner CR, Ellmore TM, Pieters TA, DiSano MA, Tandon N (2011) Variability of the relationship between electrophysiology and BOLD-fMRI across cortical regions in humans. J Neurosci 31:12855-12865. CrossRef Medline

Crone NE, Miglioretti DL, Gordon B, Lesser RP (1998) Functional mapping of human sensorimotor cortex with electrocorticographic spectral analysis-II. Event-related synchronization in the gamma band. Brain 121: 2301-2315. CrossRef Medline

Damasio H, Grabowski TJ, Tranel D, Hichwa RD, Damasio AR (1996) A neural basis for lexical retrieval. Nature 380:499-505. CrossRef Medline

Damasio H, Tranel D, Grabowski T, Adolphs R, Damasio A (2004) Neural systems behind word and concept retrieval. Cognition 92:179-229. CrossRef Medline

Devlin JT, Russell RP, Davis MH, Price CJ, Wilson J, Moss HE, Matthews PM, Tyler LK (2000) Susceptibility-induced loss of signal: comparing PET and fMRI on a semantic task. Neuroimage 11:589-600. CrossRef Medline

Drane DL, Ojemann JG, Phatak V, Loring DW, Gross RE, Hebb AO, Silbergeld DL, Miller JW, Voets NL, Saindane AM, Barsalou L, Meador KJ, Ojemann GA, Tranel D (2013) Famous face identification in temporal lobe epilepsy: support for a multimodal integration model of semantic memory. Cortex 49:1648-1667. CrossRef Medline

González IQ, León MA, Belin P, Martínez-Quintana Y, García LG, Castillo MS (2011) Person identification through faces and voices: an ERP study. Brain Res 1407:13-26. CrossRef Medline

Gorno-Tempini ML, Price CJ, Josephs O, Vandenberghe R, Cappa SF, Kapur N, Frackowiak RS, Tempini ML (1998) The neural systems sustaining face and proper-name processing. Brain 121:2103-2118. CrossRef Medline

Grabowski TJ, Damasio H, Tranel D, Ponto LL, Hichwa RD, Damasio AR (2001) A role for left temporal pole in the retrieval of words for unique entities. Hum Brain Mapp 13:199-212. CrossRef Medline

Hermes D, Miller KJ, Vansteensel MJ, Edwards E, Ferrier CH, Bleichner MG, van Rijen PC, Aarnoutse EJ, Ramsey NF (2014) Cortical theta wanes for language. Neuroimage 85:738-748. CrossRef Medline

Kondo H, Saleem KS, Price JL (2003) Differential connections of the temporal pole with the orbital and medial prefrontal networks in macaque monkeys. J Comp Neurol 465:499-523. CrossRef Medline

Lachaux JP, Fonlupt P, Kahane P, Minotti L, Hoffmann D, Bertrand O, Baciu M (2007) Relationship between task-related gamma oscillations and BOLD signal: new insights from combined fMRI and intracranial EEG. Hum Brain Mapp 28:1368-1375. CrossRef Medline

Lambon Ralph MA (2014) Neurocognitive insights on conceptual knowledge and its breakdown. Philos Trans R Soc Lond B Biol Sci 369: 20120392. CrossRef Medline

Lambon Ralph MA, McClelland JL, Patterson K, Galton CJ, Hodges JR (2001) No right to speak? The relationship between object naming and semantic impairment: neuropsychological evidence and a computational model. J Cogn Neurosci 13:341-356. CrossRef Medline

Miller KJ, Leuthardt EC, Schalk G, Rao RP, Anderson NR, Moran DW, Miller 
JW, Ojemann JG (2007) Spectral changes in cortical surface potentials during motor movement. J Neurosci 27:2424-2432. CrossRef Medline

Miller KJ, Abel TJ, Hebb AO, Ojemann JG (2011) Rapid online language mapping with electrocorticography. J Neurosurg Pediatr 7:482-490. CrossRef Medline

Morán MA, Mufson EJ, Mesulam MM (1987) Neural inputs into the temporopolar cortex of the rhesus monkey. J Comp Neurol 256:88-103. CrossRef Medline

Nourski KV, Rhone A, Steinschneider M, Kawasaki H, Oya H, Howard M (2014) Cortical representation of spectrally degraded speech: an intracranial electrophysiology study. In: 2014 Midwinter Meeting Abstract Book. San Diego: Association for Research in Otolaryngology. PS-436.

Ojemann JG, Akbudak E, Snyder AZ, McKinstry RC, Raichle ME, Conturo TE (1997) Anatomic localization and quantitative analysis of gradient refocused echo-planar fMRI susceptibility artifacts. Neuroimage 6:156167. CrossRef Medline

Oldfield RC (1971) The assessment and analysis of handedness: the Edinburgh inventory. Neuropsychologia 9:97-113. CrossRef Medline

Pfurtscheller G, Stancák A Jr, Edlinger G (1997) On the existence of different types of central beta rhythms below $30 \mathrm{~Hz}$. Electroencephalogr Clin Neurophysiol 102:316-325. CrossRef Medline

Pobric G, Jefferies E, Ralph MA (2007) Anterior temporal lobes mediate semantic representation: mimicking semantic dementia by using rTMS in normal participants. Proc Natl Acad Sci U S A 104:20137-20141. CrossRef Medline

Pobric G, Jefferies E, Ralph MA (2010a) Amodal semantic representations depend on both anterior temporal lobes: evidence from repetitive transcranial magnetic stimulation. Neuropsychologia 48:1336-1342. CrossRef Medline

Pobric G, Jefferies E, Lambon Ralph MA (2010b) Category-specific versus category-general semantic impairment induced by transcranial magnetic stimulation. Curr Biol 20:964-968. CrossRef Medline

Ross LA, Olson IR (2012) What's unique about unique entities? An fMRI investigation of the semantics of famous faces and landmarks. Cereb Cortex 22:2005-2015. CrossRef Medline

Skipper LM, Ross LA, Olson IR (2011) Sensory and semantic category subdivisions within the anterior temporal lobes. Neuropsychologia 49:34193429. CrossRef Medline
Steinschneider M, Nourski KV, Kawasaki H, Oya H, Brugge JF, Howard MA 3rd (2011) Intracranial study of speech-elicited activity on the human posterolateral superior temporal gyrus. Cereb Cortex 21:2332-2347. CrossRef Medline

Tallon-Baudry C, Bertrand O, Fischer C (2001) Oscillatory synchrony between human extrastriate areas during visual short-term memory maintenance. J Neurosci 21:RC177. Medline

Thomson D (1982) Spectral estimation and harmonic analysis. Proc IEEE 7:1055-1096.

Towle VL, Yoon HA, Castelle M, Edgar JC, Biassou NM, Frim DM, Spire JP, Kohrman MH (2008) ECoG gamma activity during a language task: differentiating expressive and receptive speech areas. Brain 131:2013-2027. CrossRef Medline

Tranel D, Damasio H, Damasio AR (1997) A neural basis for the retrieval of conceptual knowledge. Neuropsychologia 35:1319-1327. CrossRef Medline

Tranel D, Grabowski TJ, Lyon J, Damasio H (2005) Naming the same entities from visual or from auditory stimulation engages similar regions of left inferotemporal cortices. J Cogn Neurosci 17:1293-1305. CrossRef Medline

Tsuchiya N, Kawasaki H, Oya H, Howard MA 3rd, Adolphs R (2008) Decoding face information in time, frequency and space from direct intracranial recordings of the human brain. PLoS One 3:e3892. CrossRef Medline

Visser M, Embleton KV, Jefferies E, Parker GJ, Ralph MA (2010a) The inferior, anterior temporal lobes and semantic memory clarified: novel evidence from distortion-corrected fMRI. Neuropsychologia 48:1689-1696. CrossRef Medline

Visser M, Jefferies E, Lambon Ralph MA (2010b) Semantic processing in the anterior temporal lobes: a meta-analysis of the functional neuroimaging literature. J Cogn Neurosci 22:1083-1094. CrossRef Medline

Wada J, Rasmussen T (2007) Intracarotid injection of sodium amytal for the lateralization of cerebral speech dominance. J Neurosurg 106:1117-1133. CrossRef Medline

Waldron EJ, Manzel K, Tranel D (2014) The left temporal pole is a heteromodal hub for retrieving proper names. Front Biosci (Schol Ed) 6:50-57. Medline 